\title{
Article \\ Reduction of Dust on Solar Panels through Unipolar Electrostatic Traveling Wave
}

\author{
Murat Altıntaş $1, * \mathbb{C}$ and Serdal Arslan ${ }^{2}$ \\ 1 Department of Electrical Engineering, Faculty of Engineering, Harran University, Sanliurfa 63290, Turkey \\ 2 Department of Electrical, Harran University Organized Industrial Zone Vocational High School, \\ Harran University, Sanliurfa 63290, Turkey; serdalarslan@harran.edu.tr \\ * Correspondence: murat@mualmuhendislik.com.tr
}

check for

updates

Citation: Altıntaş, M.; Arslan, S. Reduction of Dust on Solar Panels through Unipolar Electrostatic Traveling Wave. Appl. Sci. 2021, 11, 9121. https://doi.org/10.3390/ app11199121

Academic Editor: Ramaraj Boopathy

Received: 20 August 2021

Accepted: 24 September 2021

Published: 30 September 2021

Publisher's Note: MDPI stays neutral with regard to jurisdictional claims in published maps and institutional affiliations.

Copyright: (c) 2021 by the authors. Licensee MDPI, Basel, Switzerland. This article is an open access article distributed under the terms and conditions of the Creative Commons Attribution (CC BY) license (https:// creativecommons.org/licenses/by/ $4.0 /)$.

\begin{abstract}
In this study, a novel electrostatic cleaning scheme has been applied to a new designed and developed electrode having high cleaning efficiency. In this method, a high voltage, four-channel, $1 \mathrm{~Hz}$ square wave signal is applied to a specially designed electrode array. Models of the electric field distribution of the proposed electrode array were developed and analyzed using Ansys Maxwell simulation software and printed circuits boards (PCBs) were produced. The performance of dust removal using the electrodes was evaluated. A $1 \mathrm{MW}$ solar power plant was taken as a case study, and performance and cost were compared with the classical panel cleaning method (wet cleaning system). Our study has shown that the electrostatic cleaning method can be carried out with lower cost and higher efficiency than existing methods.
\end{abstract}

Keywords: dust particles; dust mitigation; electrostatic; solar panel; cleaner

\section{Introduction}

The power produced by solar panels varies according to the incident radiation, which varies with location, climate, and installation. Although there is high radiation in equatorial regions, especially in desert areas, these may experience high losses due to dust and other factors, with reduction in energy obtained. The distribution of dust in different parts of the world has been investigated and significant dust accumulation is observed in the Middle East and North Africa [1]. Whilst the Middle-East is a suitable place to collect solar energy; there is an abundance of sand and dust [2]. The effects of dust accumulation have been investigated in detail and the cleaning cycle and methods based on the PM10 world map for dust removal are discussed in [3]. Turkey also has an abundance of dust due to its location that affects energy production in solar power plants. Such problems were observed in a study in Iraq [4], in which the accumulation of dust on the surface of solar panels in solar power plants (SPP) significantly reduced panel performance. The aqueous panel cleaning system of Europe is often used in Turkey, as it is recommended to clean the panel surfaces monthly with an automatic cleaning system [3]. In Middle East regions, the diameter and form of dust particles varies from region to region due to environmental and climatic factors [5]; in some regions the dust is dry, whereas in other regions it is small and sticky, causing a decrease in power [6]. Dust on photovoltaic panels can reduce the solar radiation by half [7] and has been shown to reduce the amount of electricity generated by $40 \%$ [8] and $85 \%$ [9]. For example, dust accumulation on solar panels caused a decrease in performance of $32 \%$ after 8 months in Riyadh and 17\% after 6 days in Kuwait [10]; periodic cleaning of panels is essential. Moreover, cleaning solar panels in this region can be problematic due to the scarcity of water [2], and such aqueous and manual cleaning is expensive for large-scale power plants [11]. Alternative cleaning methods to the traditional water or mechanical assemblies should be investigated [2,10,12-16]. A new four-stage automatic 'dry cleaning' method for solar panels has been reported [2]; [17] investigated dust removal methods including natural tools, mechanical tools, electrostatic tools and self-cleaning nano-film; a 
piezoelectric actuator-based cleaning system with a light weight and compact structure was reported in [18]. An ultrasonic cleaning method has been proposed that can access hard-to-reach surfaces that are not normally accessible [19].

A moving wave electric charge has been investigated as a method to clean small particles from solar panels [20]. The electrostatic method is based on cleaning dust by applying high voltage to parallel electrodes embedded in the glass plate of the panels [21]. Cleaning systems using a similar method have been developed to remove dust and sand from the surfaces of solar panels [22,23]. The glass plate of a solar panel is embedded with parallel wire electrodes for single-phase [21], two-phase [23,24], three-phase [8,25] or fourphase [23-26], with a high voltage being applied. In this approach, power consumption is very low [21]. This system is especially suitable for use in the very large SPP built in deserts because it can clean automatically in a way that is low-power, cheap, and avoids water cleaning [21]. However, cleaning panels by an electrostatic method requires very high voltages to work efficiently, which can be difficult practically and dangerous to working staff [2]. One study [21] found that the electrostatic method removed more than $90 \%$ of the dust particles from the surface of an inclined panel [21]. This system is reliable because it has no moving parts [23]. The electrostatic method has been shown to be capable of cleaning a panel surface loaded with sand up to $300 \mathrm{~g} / \mathrm{m}^{2}$, giving high performance corresponding to a sand layer thickness of about $0.3 \mathrm{~mm}$. Moreover, cleaning performance has been found to increase with a weak wind parallel to the direction of the plate, although high wind speed increases dust accumulation [21]. If the sum of the electrostatic force and wind force are greater than the sum of the gravitational force and the bonding force between the particles and the glass plate, dust particles will be removed from the panel [23]. The gravitational force should not be neglected as the specific gravity of the dusts and the slope of the cleaning plate are changed by the location where the SPP is located [23].

Electrostatic cleaning works by ionizing the dust on the surface of the solar panel with an electrostatic precipitator and then pushing the dirt from the panel using a set of electrodes [16]. The dust precipitator has varying efficiency for removal of dust depending on voltage and operating conditions [27]. Electrodynamic dust shields [28-30] and electric curtains for dust removal have been proposed [31]. It has also been determined that dust particles can be cleaned from the surface of panels by hydrophobic wetting under an electrostatic effect [32].

Dust particles consist of the oxide of many elements, including $\mathrm{Si}, \mathrm{O}, \mathrm{Ca}, \mathrm{K}, \mathrm{Na}$, $\mathrm{Cl}, \mathrm{S}, \mathrm{Fe}$ and $\mathrm{Mg}$, with various shapes and sizes [6,32]. Other, rarer, elements are also found, including $\mathrm{Nb}, \mathrm{Cl}, \mathrm{Ti}, \mathrm{P}, \mathrm{Fr}, \mathrm{Au}$ and $\mathrm{Ba}[6]$. During humid weather conditions, water condensation on the dust particles creates a chemically active solution, that adheres strongly to the surface of the panels and improves the adhesion of the dust particles [32]. This can make it difficult to remove dust particles by the electrostatic method. Particle size is also important. For example, dust particles in Doha, Qatar, have an average diameter of $2.3 \mu \mathrm{m}$ [14]. Particles larger than $25 \mu \mathrm{m}$ in diameter and smaller than $300 \mu \mathrm{m}$ in diameter are efficiently cleaned by the electrostatic method [21]. This can be explained by small-sized dust particles forming clusters around large-sized particles and small-sized particles remaining in the air longer than large-sized dust particles and resettling [32]. In addition, small particles tend to stick to the surface of the glass, reducing the efficiency of the cleaning system [21,23]. For large particles, their heavier weight prevents them from bouncing and moving [21]. Therefore, other approaches are investigated to improve cleaning performance. One way to improve electrostatic cleaning efficiency is to create a stronger electrostatic force at high voltage [23]. Cleaning efficiency is improved when the thickness of the cover glass is thin due to the reducing distance from the electrodes to the surface of the cap glass, and a high electrostatic field is formed on the cap glass surface [23]. This field pushes and removes the dust particles from the surface of the glass, regardless of whether the dust particles were initially charged [8]. One study [24] modeled the electrostatic particle removal as a thrust, sliding and rolling mechanism. Another study 
showed that dust can be displaced on an inclined panel using low-frequency high-voltage electricity [23].

When a single-phase square wave voltage is applied to parallel electrodes, a moving wave is not produced and, while the particles are pushed off the plate, they are not transported in any direction and are transported downwards by gravity [21]. One study applied a voltage of $1 \mathrm{kV}$ p-p to parallel electrodes with diameter of $0.3 \mathrm{~mm}$, length of $100 \mathrm{~mm}$, and placed at an interval of $4 \mathrm{~mm}$ [32]. The use of a hydrophobic surface showed that dust residues can be removed by subjecting dust particles to an electrostatic force. One study [21], using a voltage of $9.8 \mathrm{kV}$ for $10 \mathrm{~mm}$ and $8.4 \mathrm{kV}$ for $7 \mathrm{~mm}$ at low frequency (less than $20 \mathrm{~Hz}$ ), achieved a maximum cleaning efficiency of about $80 \%$. At low voltages $(0.7 \mathrm{kVp}-\mathrm{p})$ the dust continues to adhere to the surface, whereas at high voltages $(11.8 \mathrm{kVp}-\mathrm{p})$ the dust is displaced by the same electrodes [28]. Varying the applied frequency from 0.5 to $10 \mathrm{~Hz}$ alters the transport distance of the loop, with the maximum transport distance being provided at a frequency of $1 \mathrm{~Hz}$ [28]. At low frequencies, the cleaning performance is increased because the particle motion can follow the polarity change [21].

In an alternative electrostatic cleaning method, the electrostatic cleaner produces a standing wave that does not move the particles in one direction, rather it causes a "flip-flop" movement of the particles on the surface of the plate and they are carried in the air and down by gravity [23]. An accumulation of dust of over $90 \%$ can be removed in 2 min by the moving wave generated by the applied electric field [11]. If the electrostatic cleaner is operated intermittently, dust that adheres to the glass of the solar panel is displaced. In the case of continuous operation, dust approaching the cover glass is also displaced [21].

The adhesion of dust particles is affected by the time of day, and water condensation at night will increase contamination on the solar panel [33]. When the plate surface is wet due to precipitation or dew, or when there is a sandstorm and precipitation together, the accumulated dust will adhere strongly to the plate [21]. This makes cleaning difficult. However, high performance in cleaning can be achieved after the plate has dried [21]. Poor performance was observed for extremely small dust particles [23]. It is suggested performance will be improved by applying a high voltage to reduce the adhesion force, using natural wind, and using frequent operations before dust accumulates [21]. Improving the cleaning of dust particles can be considered as improving the electrode configuration, adjusting the operational scheme, and using airflow [34].

The energy consumed in the cleaning system is proportional to the applied voltage, the number of working cycles, and the operating time of the system, although energy consumption can be extremely low with a simple and potentially cost-effective electrostatic cleaner [21]. It has been found that an electrodynamic cleaning system can achieve a reduction in dust pollution between $32.1 \%$ and $95.7 \%$ [35]. This can provide efficient operation for large-scale SSP built in deserts around the world [34] and may also be used to remove dust from solar visors, and surfaces such as solar panels on extra-terrestrial missions [26,29,30,33,36-39].

The dust removal electrode is composed of an insulation material and a wire electrode, and dust removal performance is affected by the insulating material, the geometry of the copper electrode [33]. The efficiency of electrodes with the same copper area but different design (planar, thick-toothed comb, and thin-toothed comb) to remove powder has been investigated [33]. The comb-shaped dust removal electrode was found to provide better cleaning performance compared to the planar electrode [33].

It has also been shown that under electrostatic and hydrophobic conditions, not only are environmental dust particles removed but, by reducing the adhesion of dust particles on the surface on the hydrophobic surface, more dust particles are removed [32].

The Electrodynamic Screen (EDS) will be one of the particle removal technologies used for space travel (Moon, Mars, etc.) [26,29,36,37]. The Electrodynamic Shield is to be used to clean particle from the surface of the solar panels on Mars [29]. It has been shown how uncharged particle can be lifted and extracted from solar panels under the environmental 
conditions of Mars, with an average power consumption under various dust loads and on a screen with an active surface area of $59 \mathrm{~cm}^{2}$ that was found to be 1.02 to $2.87 \mathrm{~mW}$ [37]. The power loss in the solar panel increased by $15 \%$ before the dust was removed [37]. The technology has other potential benefits for removing dust from sun visors, sight fields, and many other surfaces such as sun strings [38]. The lunar environment may hinder NASA exploration missions [30] due to the dust particles on the Moon (average $72 \mu \mathrm{m}$ ), which can adhere to the surfaces [33]. A method for protecting spacesuits from lunar dust has been developed using carbon nanotube technology [39]. Moon dust accumulated on the surface of solar panels can be cleaned by electrostatic methods and the cleaning devices can be charged with the help of solar UV irradiation, wind and cosmic rays [38]. Moreover, moon dust removal should be able to be performed more easily in a low gravity environment [26,36]. Electrostatic systems are also being developed as sampling systems to perform reliable and autonomous sampling of regolith from asteroids [36].

Efficiency of dust removal for a wide variety of particle size distributions varies with the geometric parameters of the electrode [40]. Tests conducted to determine the effect of different factors on the dust removal performance, including electrode shape, electrode thickness, electrode area, insulating film [33] provide information on electrode design to optimize the efficiency of photo-voltaic (PV) panels used in future lunar exploration. The main parameters were [37]:

- Electrical power requirements and dust accumulation rates

- Frequency of the operation of the screens

- Efficiency of EDS and Dust Removal Efficiency

- Placement of EDS system on the solar panels to reduce power loss in PV panel and increase optical transmission efficiency.

Studies on PV panel cleaning focus primarily on the design and performance of cleaning robots. However, there are few on the electrostatic cleaning method [41] although it is believed that electrostatic cleaning method can make a significant contribution.

In our previous studies, pollution data was obtained using analytical and experimental methods to determine content and impact on energy loss in PV panels [6]. Dust pollution is seen to have seasonal variation, which will cause varying losses in SPP and cleaning costs [42].

This study proposes a design for the electrodes of an electrostatic cleaning system that will reduce the contamination caused by atmospheric transported particulates on a solar panel. The electronic controller is examined in Section 2. The electric field and design of the electrode array and PCB are analyzed using numerical analysis with the Ansys Maxwell simulation software in Section 3. The performance of the proposed electrode array is compared with a traditional parallel electrode array. Then, a case study of the cleaning of 1 MW SPP in Şanliurfa province to compare costs of cleaning by a water system and the electrostatic method in Section 4. The results of the study are included in Section 5.

\section{Controller Card for Electrostatic Cleaning System}

A controller card was designed to drive the high voltage transformers of the 4 channels at the desired frequency $(1-5 \mathrm{~Hz})$ and voltage (3-11 kV) [43]. Figure 1 shows; (a) the card and I/O signals, (b) display and (c) waveforms.

The usual approach to electrostatic cleaning is for the single-phase excitation to move as the positive and negative cycle $(+\mathrm{V},-\mathrm{V})$ of two walking waves moving in opposite directions [8]. However, this study is novel in taking the output from each channel during the positive cycle, as shown in Figure 1c. 


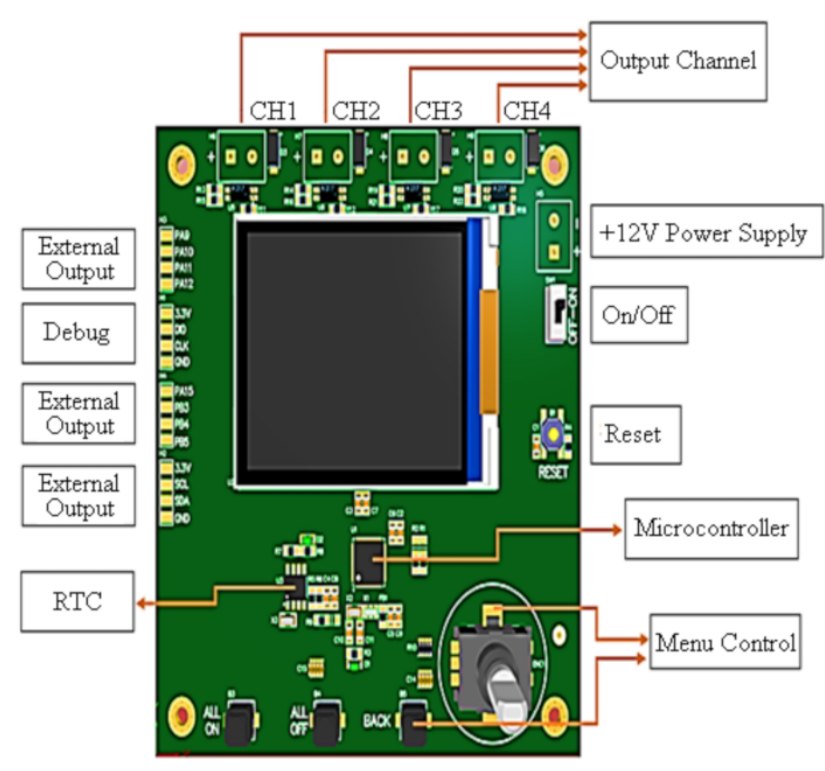

(a)

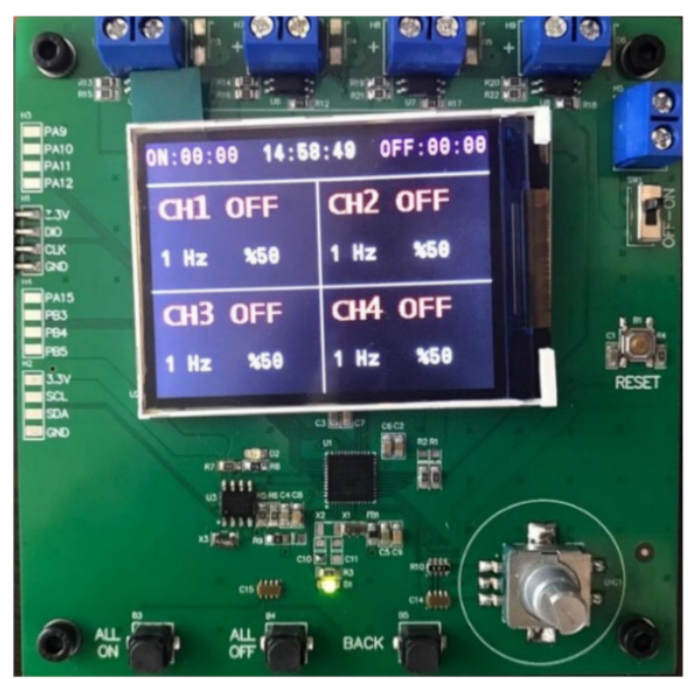

(b)

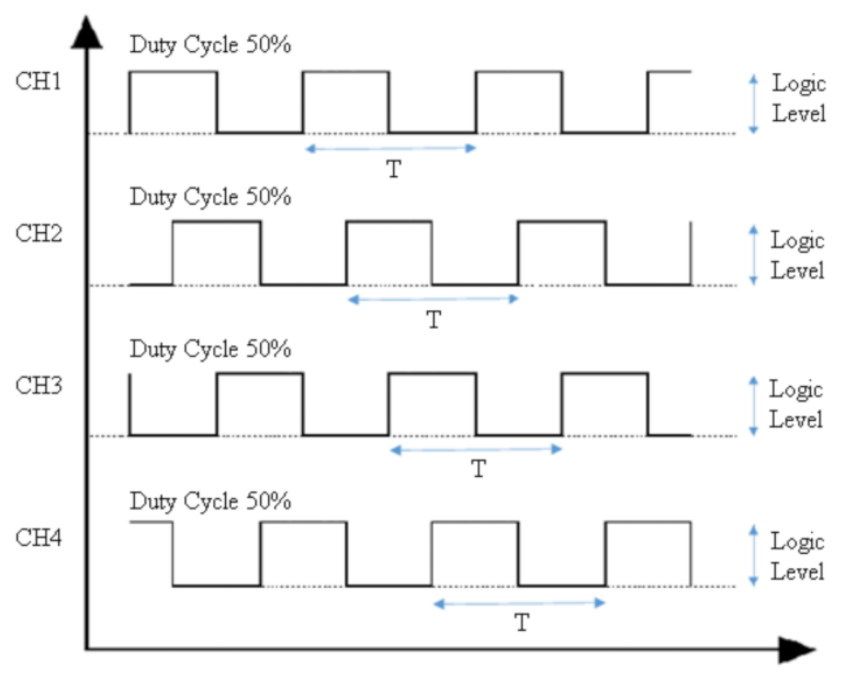

(c)

Figure 1. Electrostatic cleaner card: (a) Controller card and I/O signals, (b) Display, (c) Waveforms.

\section{Electrode Design}

The design of the electrodes is considered to create a uniform electric field between them, and therefore the distribution of the electric field may be assumed as V = Ed, where $\mathrm{V}$ is the potential between the electrodes and $\mathrm{d}$ is the electrode separation. For an electrode separation of $26 \mathrm{~mm}$ and potential of $11 \mathrm{kV}$, the electric field will be $4.23 \times 10^{5} \mathrm{~V} / \mathrm{m}$, which is less than the air breakdown value E0 $=3 \times 10^{6} \mathrm{~V} / \mathrm{m}$. In one simulation study, the width of the electrodes as copper tracks (electrodes) on Fr4 material with $2 \mathrm{~mm}$ thickness was considered to be $0.1 \mathrm{~mm}$ and a potential was applied between the electrodes as a single channel using $11 \mathrm{kV}$ and $0 \mathrm{~V}$ [28]. It was observed that as electrode width increases, then the particles were attracted more strongly to the negative electrode, resulting in the particles travelling a greater distance in the same time period. It was also noted that the optimal width of the electrodes to produce greatest transport distance was $0.3-0.5 \mathrm{~mm}$. This study therefore uses an electrode width of $0.4 \mathrm{~mm}$. However, as separation between electrodes increases, the electric field decreases [28,44], and this study has selected a separation 
between the electrodes of $26 \mathrm{~mm}$. This study investigates four designs for the copper electrodes. In order to examine the electric field changes of the models, three separate lines passing along the main axis of the panel from top to bottom were drawn (Figure 2).

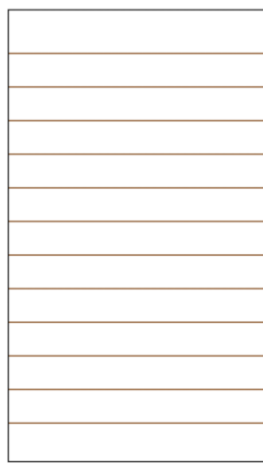

M1 MODEL

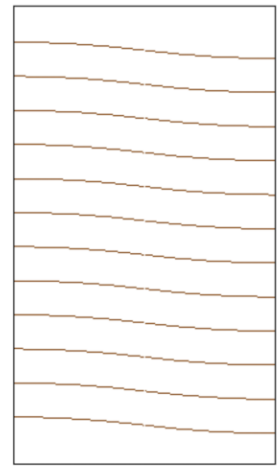

M2 MODEL

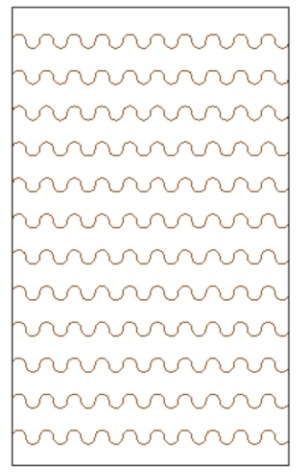

M3 MODEL

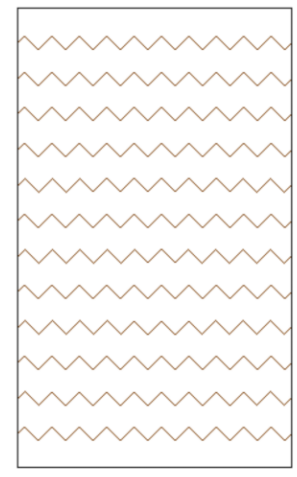

M4 MODEL

(a)
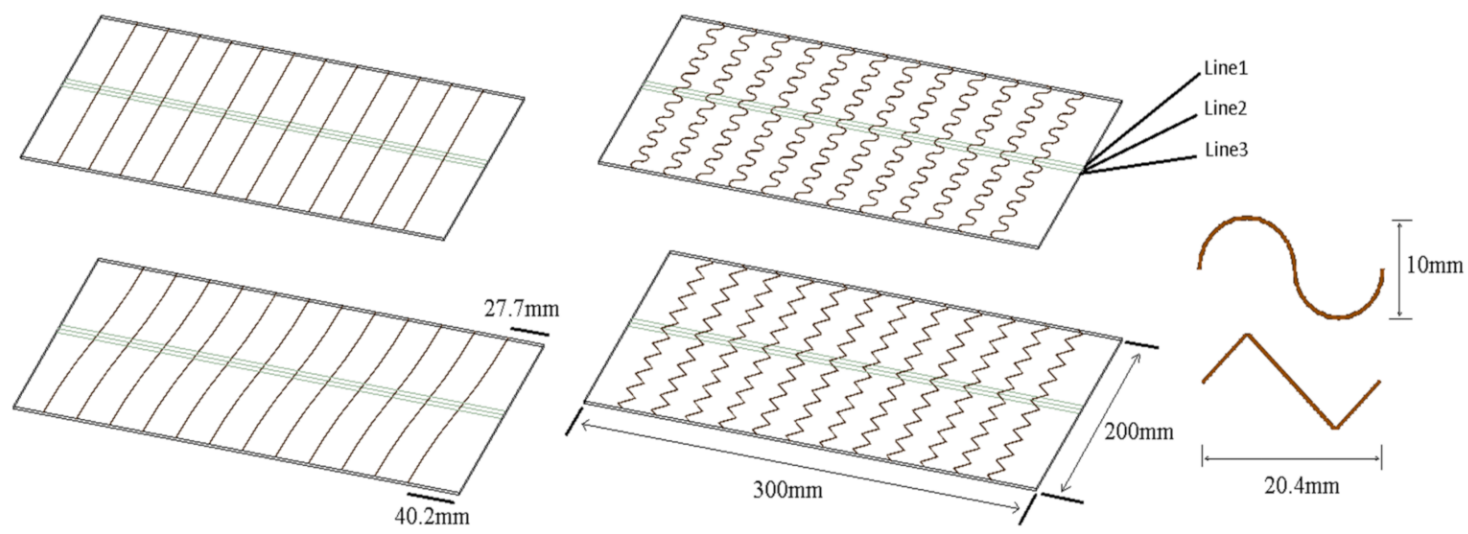

(b)

Figure 2. Electrode array models: (a) two-dimensional view of models; (b) view of models.

Models of the electrode array were developed using the Ansys Maxwell 3D Electrostatic Solver software simulation package. This uses finite element method (FEM) to solve two/three-dimensional (2D/3D) eddy current, electrostatic, magnetostatic, dc conduction, and transient problems. Table 1 summarizes the simulation process of the 3D models with the calculation time of the finite element analysis (FEA), the total number of elements, and the energy error.

Table 1. Comparison of 3D Finite Element Analysis simulation.

\begin{tabular}{ccccc}
\hline Analysis Data & M1 Model & M2 Model & M3 Model & M4 Model \\
\hline Total number of model elements & 848,914 & $2,514,898$ & $1,257,488$ & 876,010 \\
\hline Energy error (\%) & 0.653 & 0.407 & 0.401 & 0.694 \\
\hline Analysis time (min) & $14: 09$ & $56: 57$ & $25: 54$ & $13: 07$ \\
\hline
\end{tabular}

Routing the copper tracks away from being parallel lines affects the distribution of the electrical field. An electric field becomes concentrated in areas where there are sharp lines [8], distorting the electric field. This will affect the drift rate that can be produced to transport particles away from the surface. The distribution of the electric field in each of the 4 models, with detail around the lines, is shown in Figures 3 and 4. 
Figure 4 shows the detail of the distribution of the electric field around the regional transitions of the wires. It is expected that the electric field distribution in M3 and M4 will result in greater dust movement than in M2 and M1 [38]. However it is difficult to calculate analytically the net thrust produced at the panel surface to cause the particles to take off that is given by gravitational force, the electrodynamic force, and viscous force [30,38].

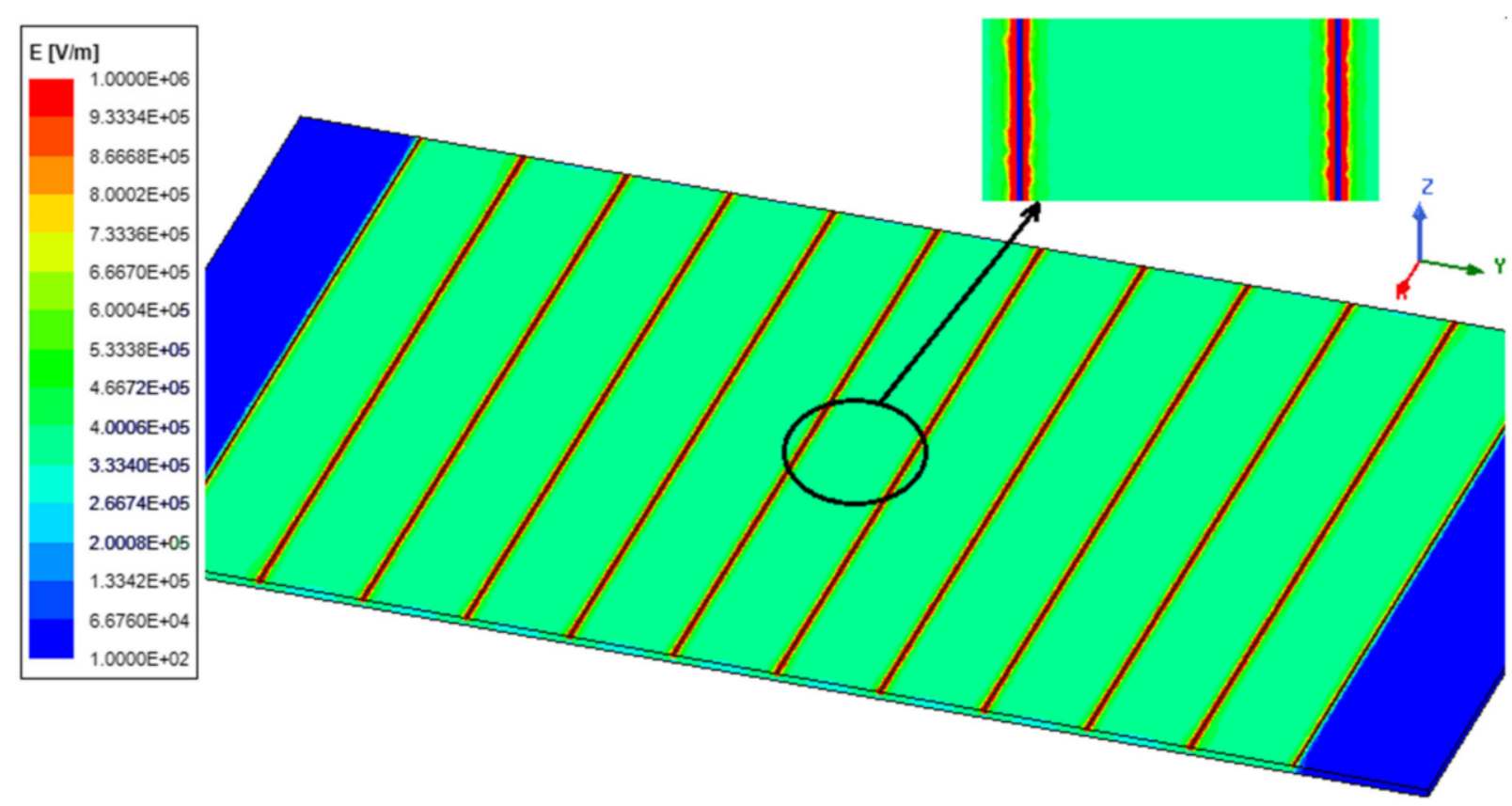

(a)

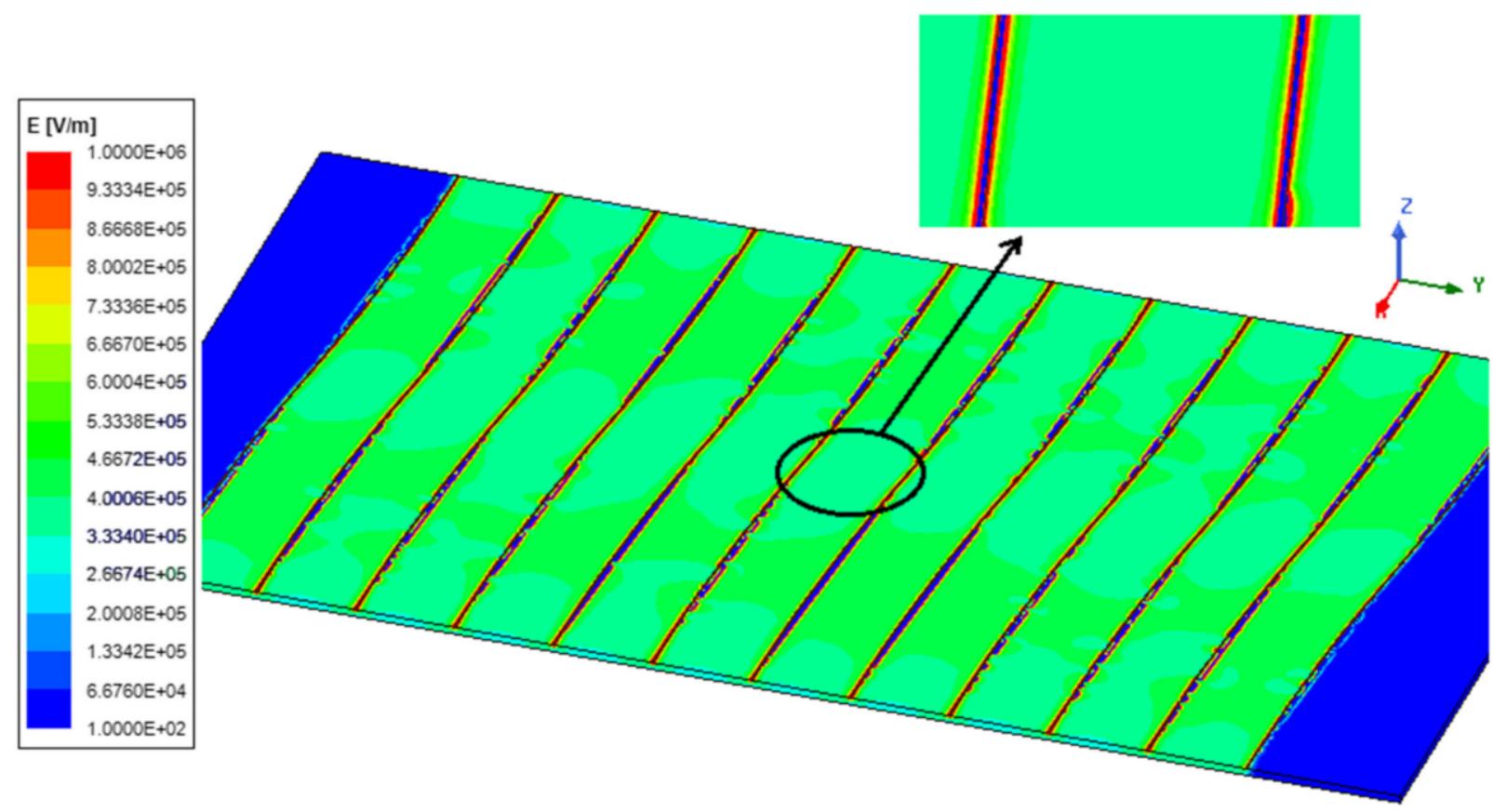

(b)

Figure 3. 3D FEA electric field distribution: (a) M1 model, (b) M2 model. 


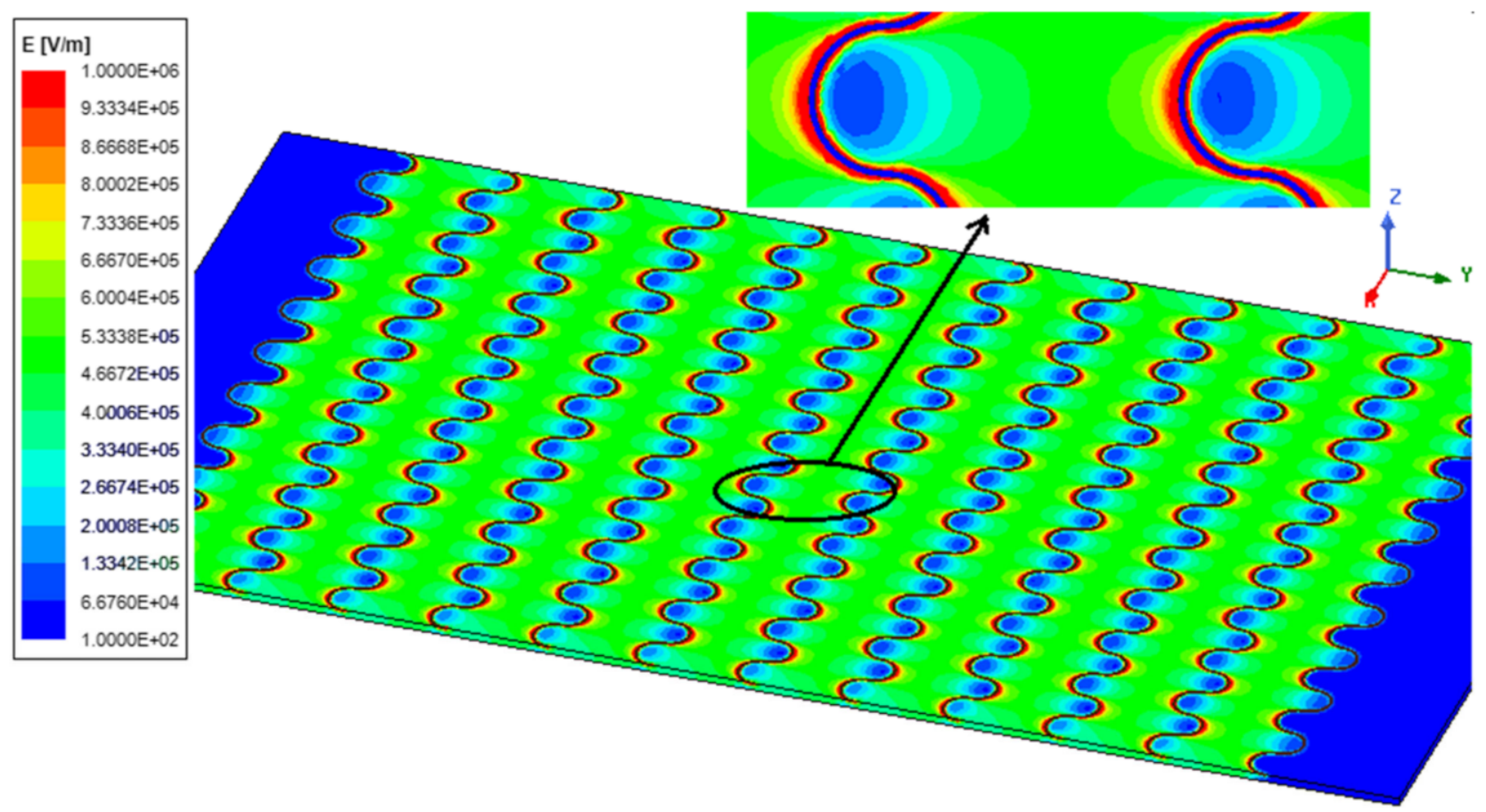

(a)

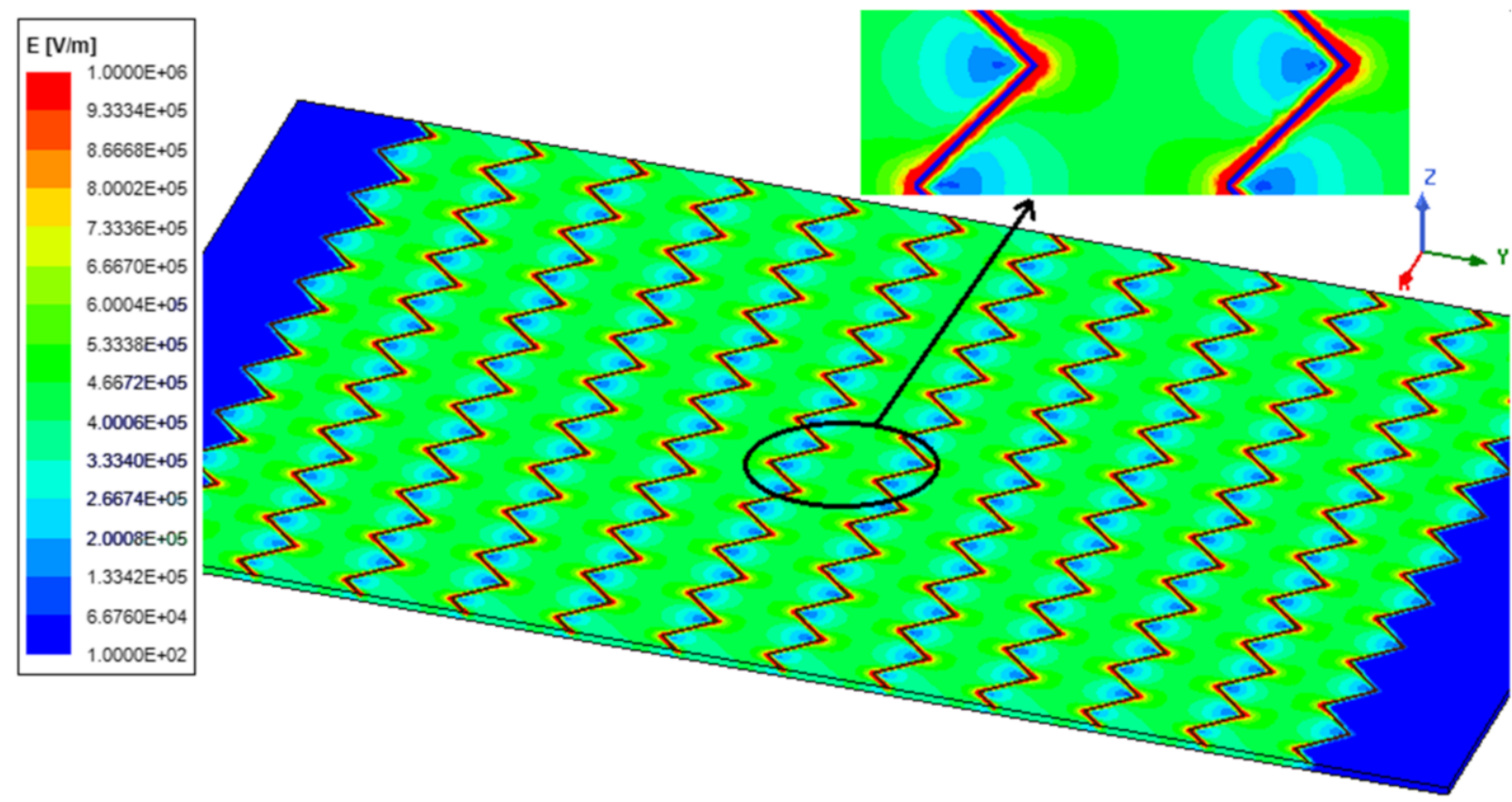

(b)

Figure 4. 3D FEA electric field distribution: (a) M3 model; (b) M4 model.

M1 has a uniform electric field distribution, while M2 is little different from a uniform electric field. Note also that the distribution of the electric field between the top and bottom of the plate is not uniform. Figures 5 and 6 show the magnitude of the distribution in detail along three lines passing along the main axis of the panel from top to bottom.

Figure 5 shows the electric field distributions are very similar in M1 and M2, although the maximum value of the electric field in M2 is about 1.7 times that of M1. In addition, the 
electric field of M1 is more homogeneous than M2, which is due to the shape of the line, as seen in Figure 5b.

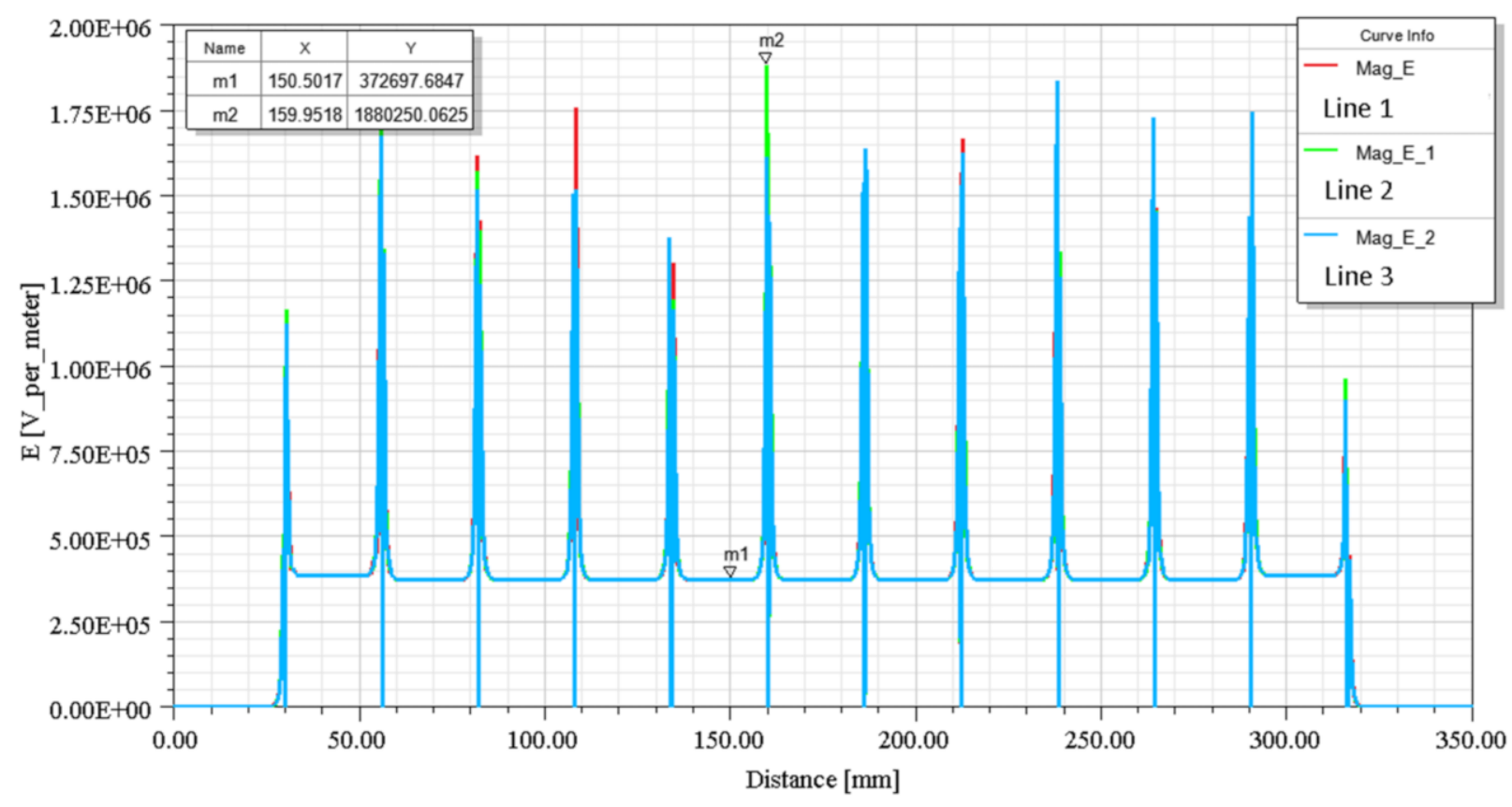

(a)

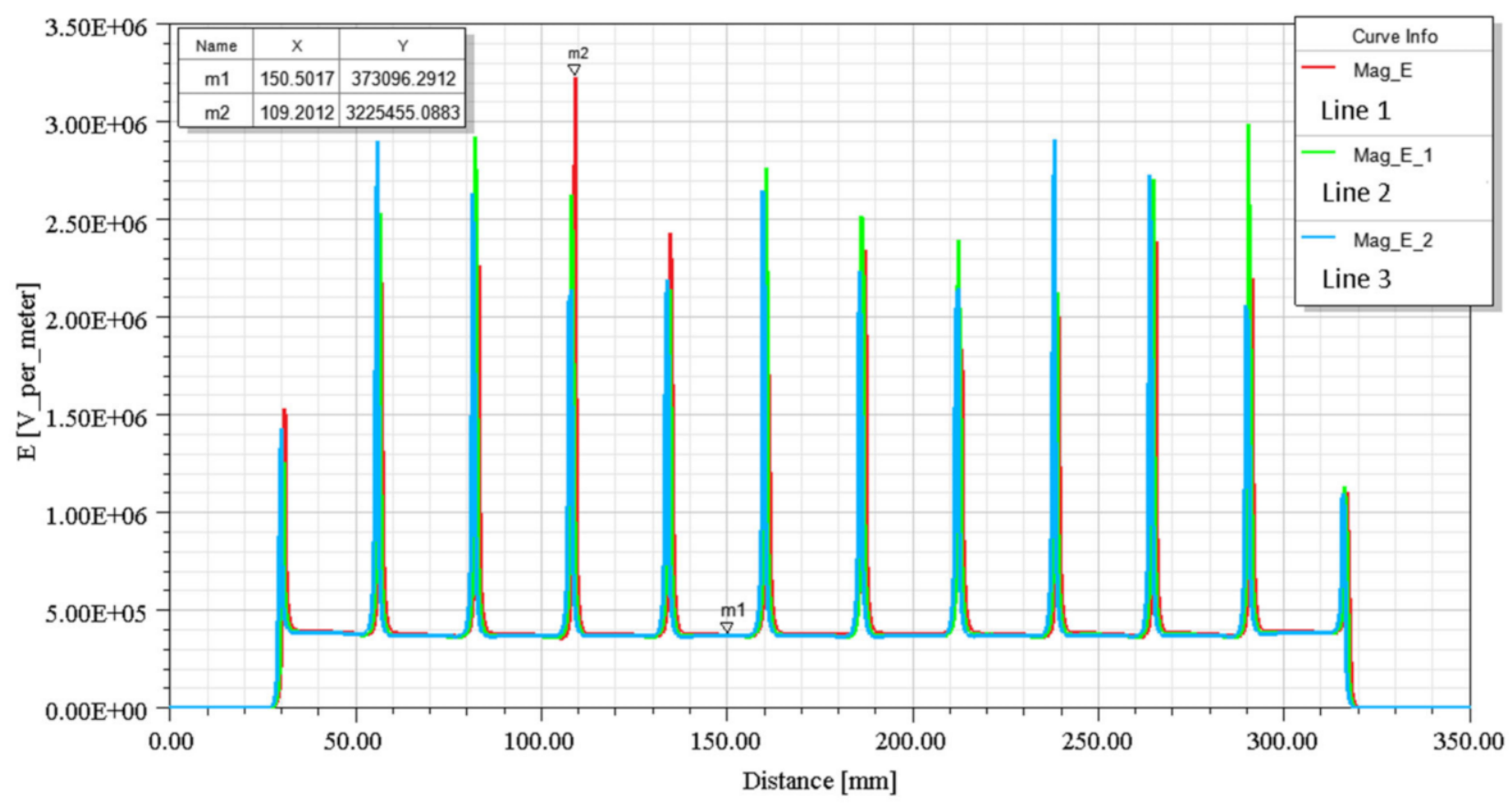

(b)

Figure 5. Electric field along the main axis of the panel: (a) model M1; (b) model M2. 


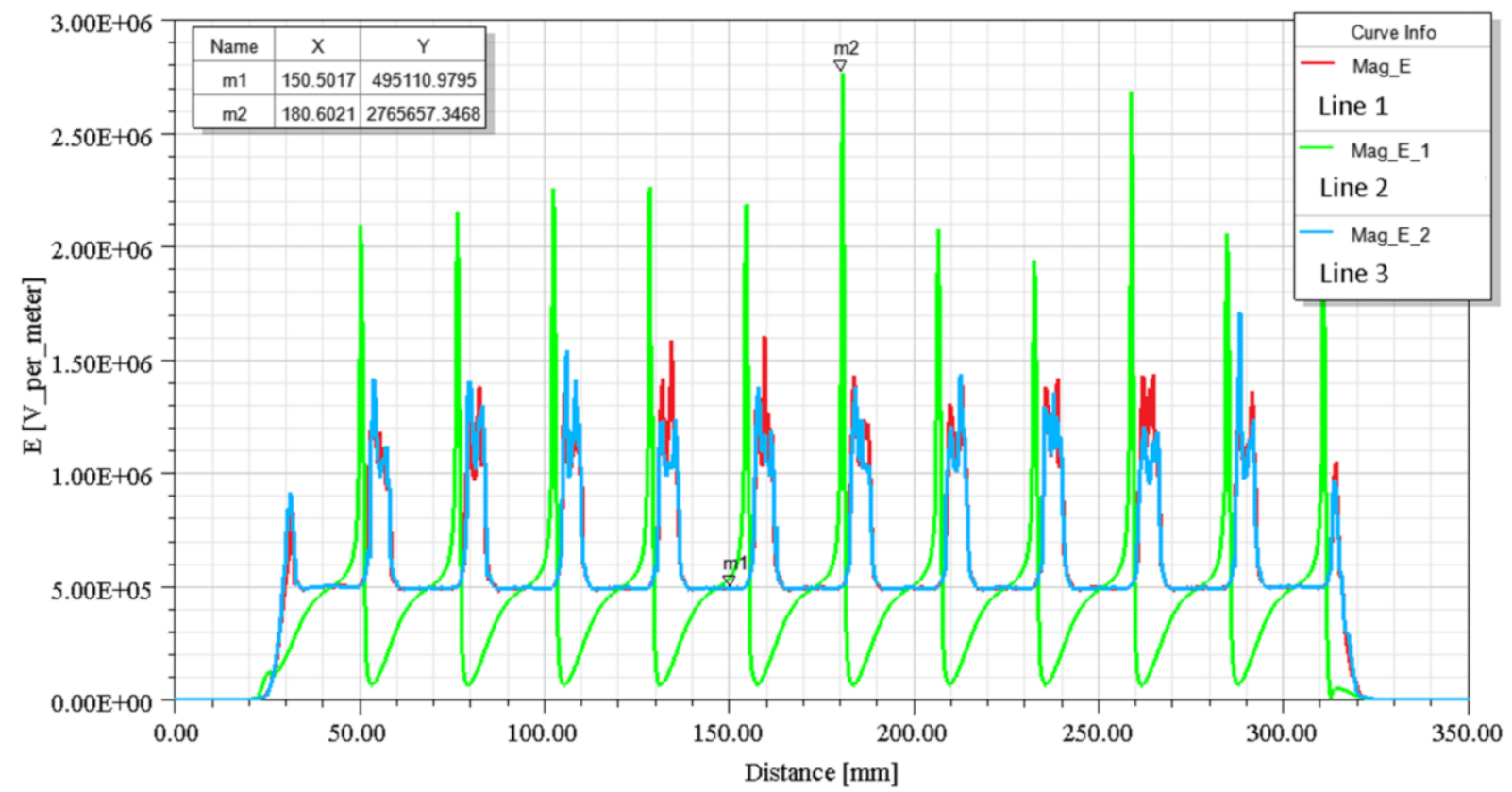

(a)

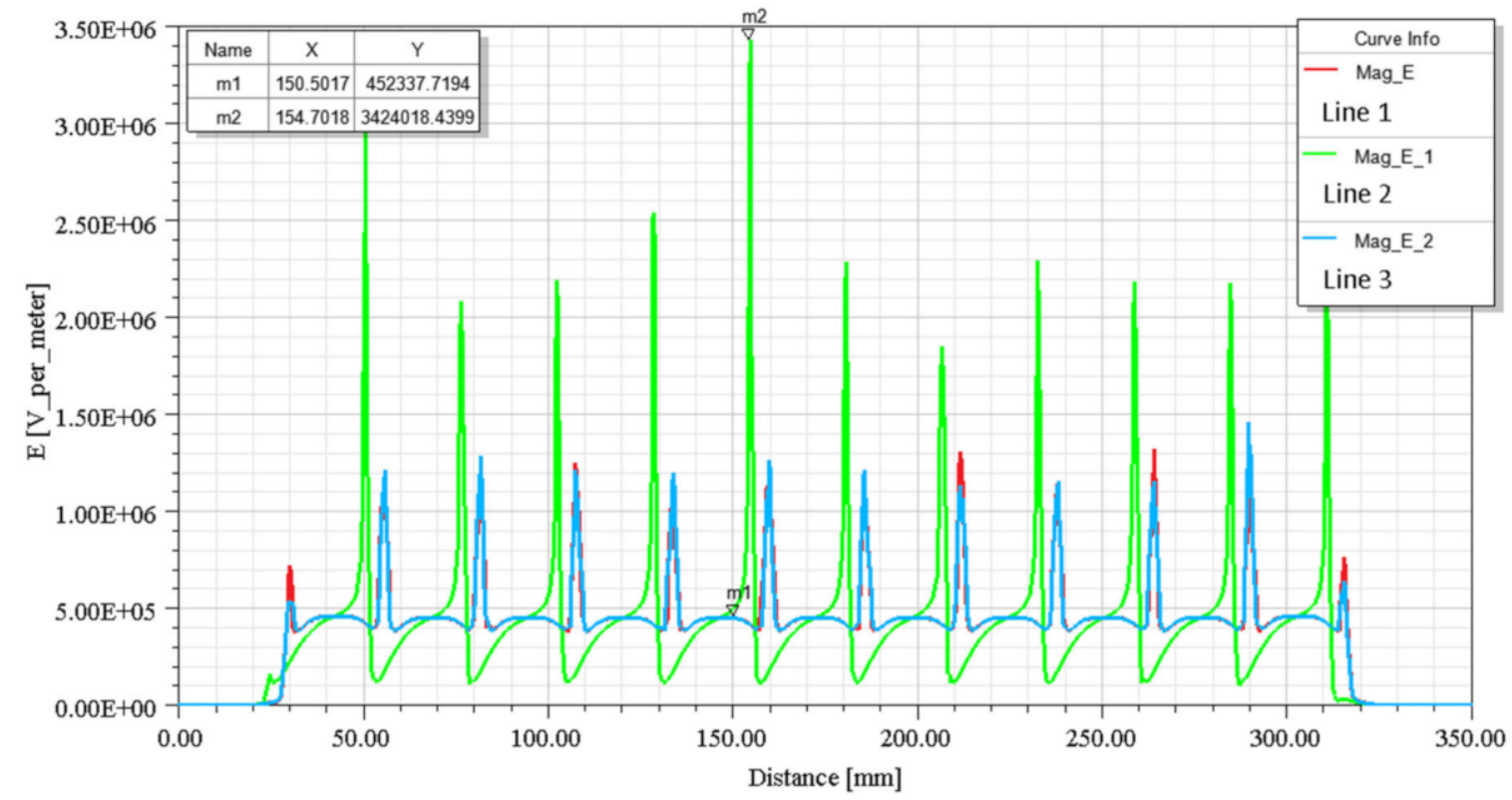

(b)

Figure 6. Electric field along the main axis of the panel: (a) model M3; (b) model M4.

The curved (sine) geometry of the M3 electrode results in a varying distribution of the electric field across the plate, and this is shown by the three lines of Figure 6a, where line 1 and line 3 pass through the "top" and "bottom" of the curve, and line 2 passes through the "zero point" of the curve. Likewise the triangular geometry of the M4 electrode results in a varying distribution of the electric field across the plate, and this is shown by the three lines of Figure $6 \mathrm{~b}$, where line 1 and line 3 pass through the "top" and "bottom" vertices of the line and line 2 passes through the "zero point" of the line. The ratio between the maximum and minimum values of the electric field of M4 was found to be 1.23. 


\section{Experimental Studies and Evaluation \\ 4.1. Electrostatic Cleaning}

The designs of M1, M2, M3 and M4 were produced as PCBs with electrodes as $0.4 \mathrm{~mm}$ wide copper tracks (Figure 7). Terminal connections were made to allow the card (Figure 8) to operate in different modes (single channel and four channels).

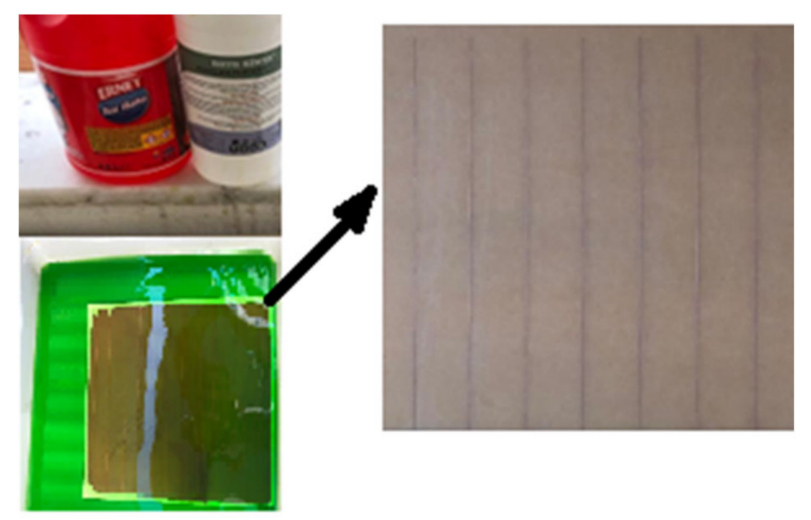

Figure 7. PCB implementation of model electrodes.

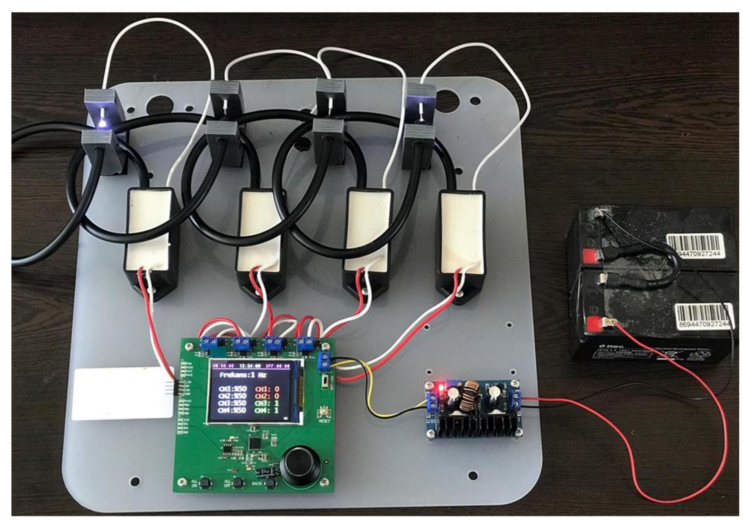

Figure 8. Working test of the experimental system.

Dust consists of oxide structures of some elements found in nature [6,32]. Although these elements and compounds are linked to the local geological structure [32], they have a significant effect on the dust removal performance (cleaning efficiency, take-off time, etc.) from the solar panel [45]. For this reason, dust analysis was performed in a previous study for the Sanliurfa province in Turkey [6]. Monthly dust samples were analyzed to determine dust size and grain content [6]. Particle size ranges from approximately $10 \mu \mathrm{m}$ to $450 \mu \mathrm{m}$ [6]. Powder with sizes between $100 \mu \mathrm{m}$ and $300 \mu \mathrm{m}$ was obtained for use in this study, as it was readily available. In addition, the electrostatic method has a high cleaning efficiency between $100 \mu \mathrm{m}-300 \mu \mathrm{m}$ depending on the particle size in cleaning the solar panel [21].

The analysis of the powder sample was carried out in the HÜBTAM Laboratory at Harran University in Turkey. In line with these analyses, scanning electron microscope (Carl Zeiss AG-EVO ${ }^{\circledR} 50$ Series) image, elemental content, and oxide forms (X-RAY Diffractometer, RIGAKU) were obtained. In addition, the density of the sample was measured. Figure $9 \mathrm{a}-\mathrm{c}$ show scanning electron microscope (SEM) micrograph of powder particles, elemental composition of the powder and the X-ray diffractogram of the powder particles, respectively. 


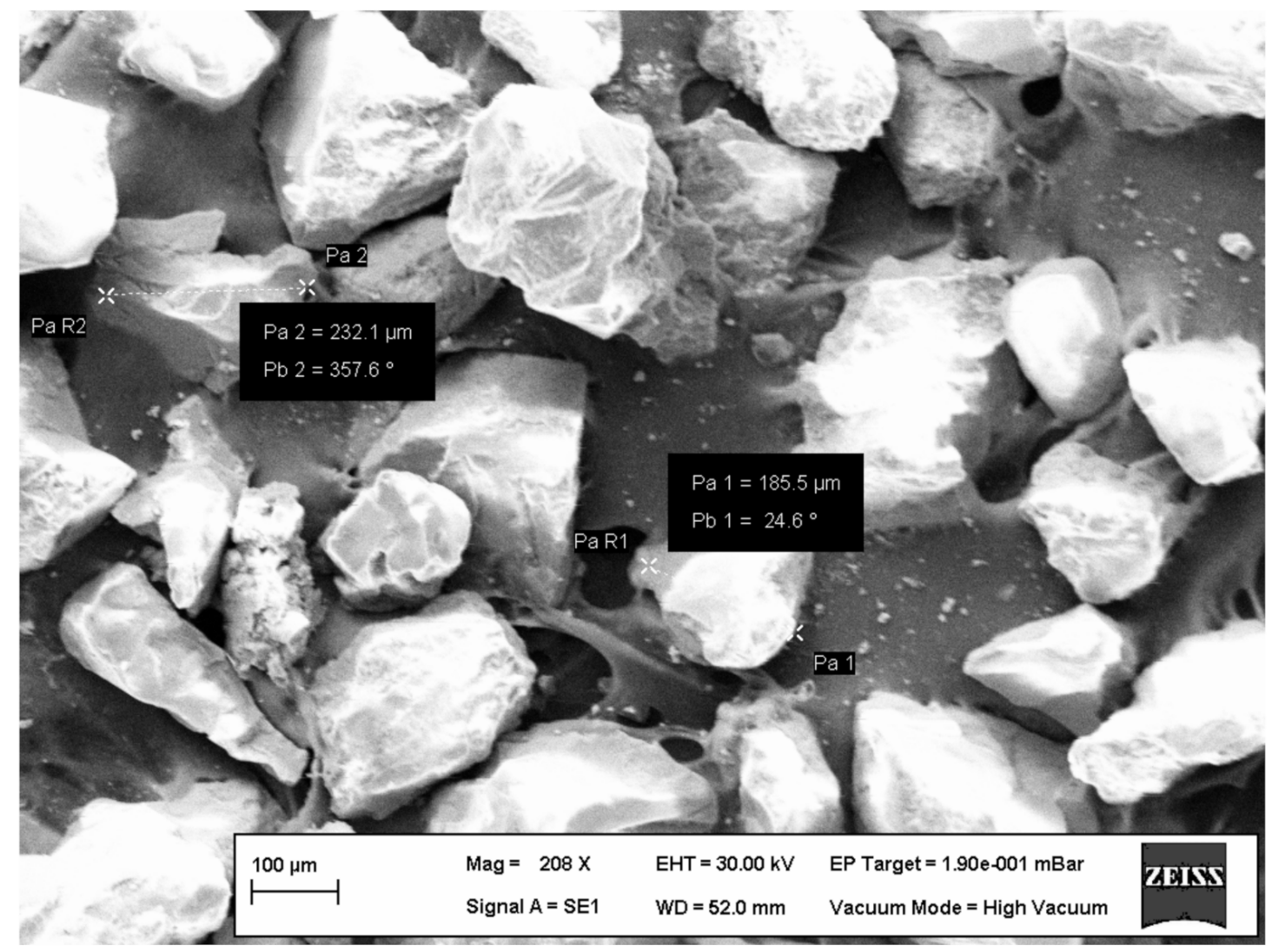

(a)

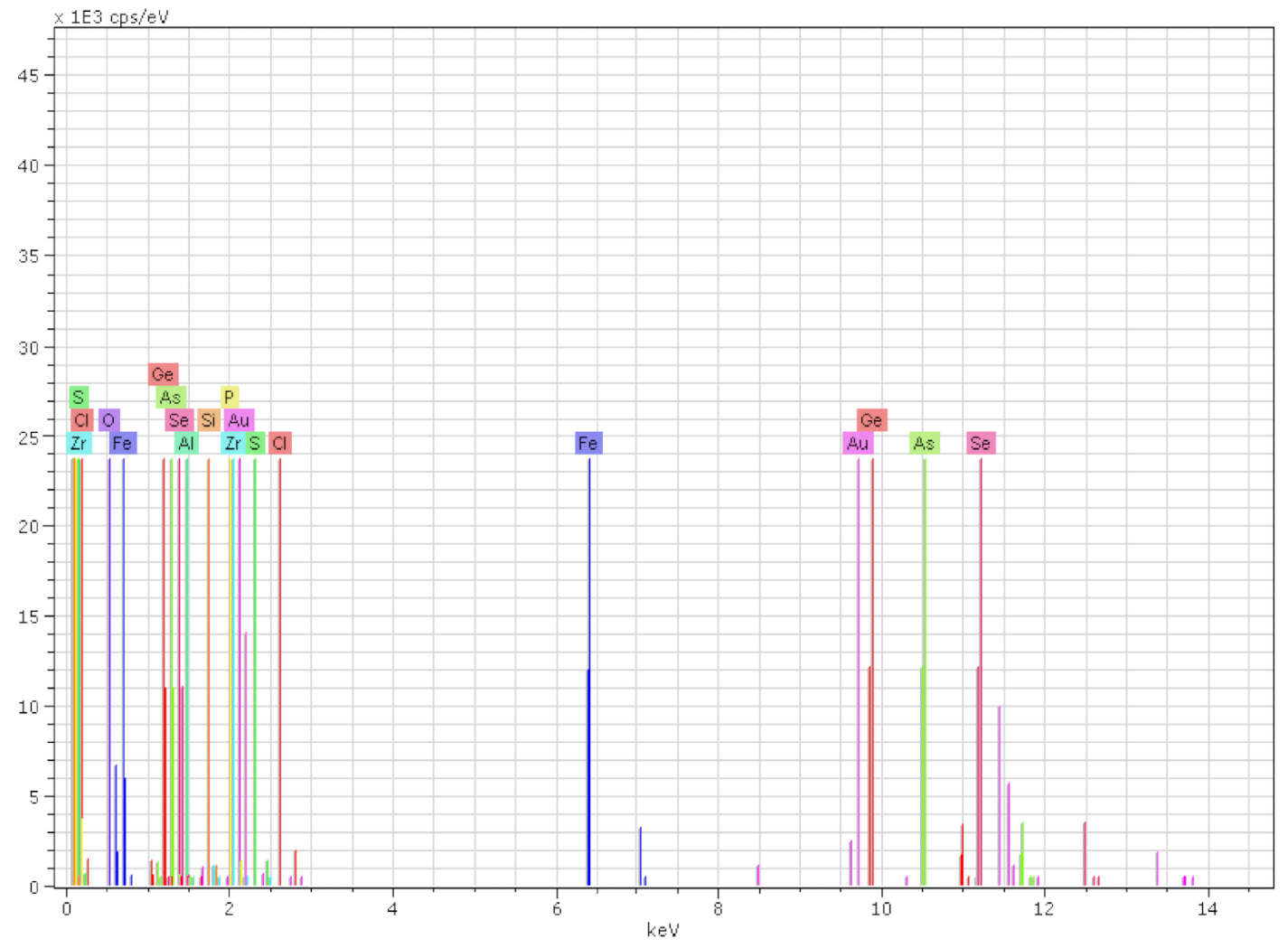

(b)

Figure 9. Cont. 


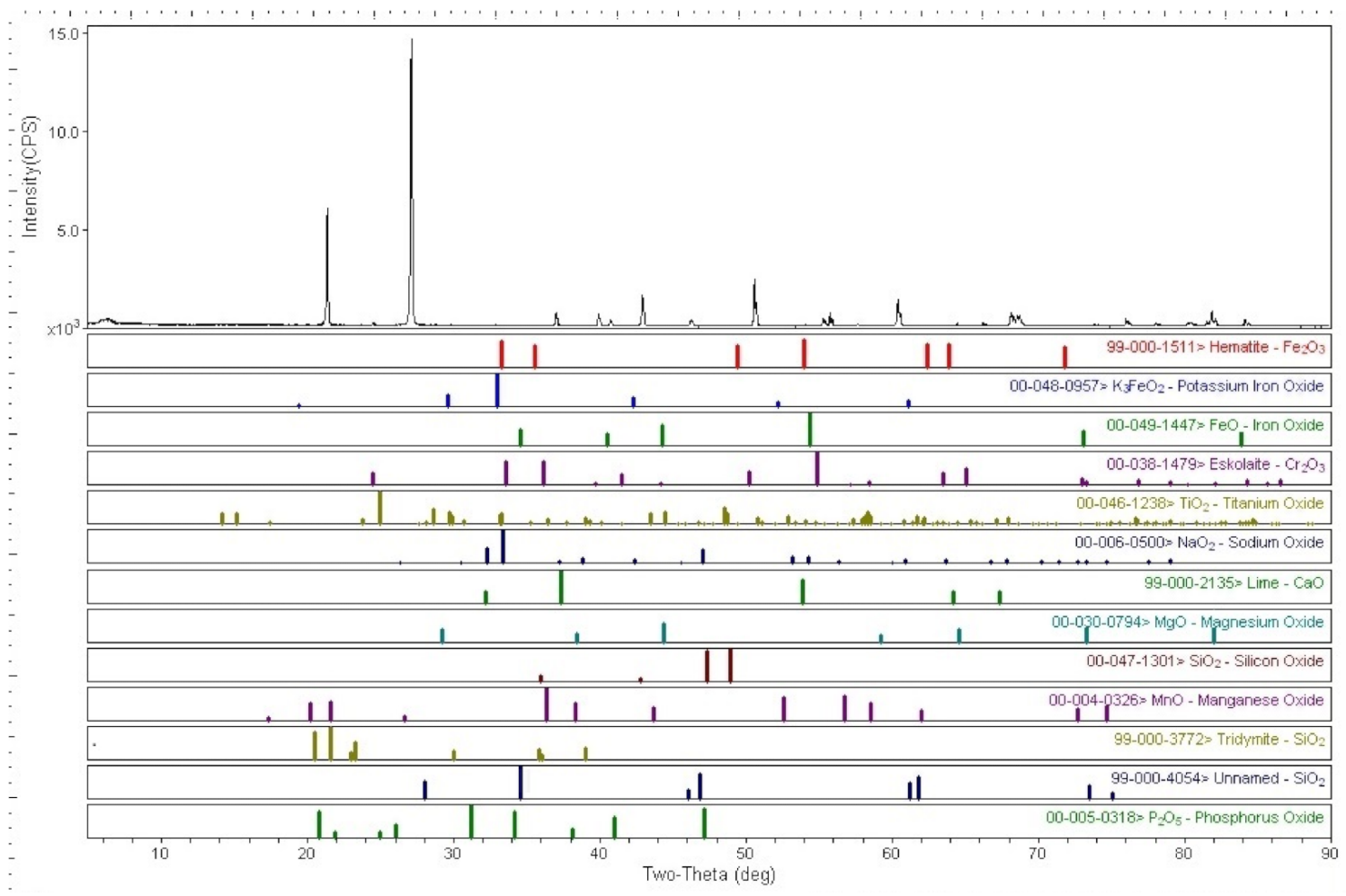

(c)

Figure 9. The powder analysis result pictures: (a) scanning electron microscope image of the powder; (b) Elemental composition spectrum of the powder; (c) X-ray diffraction intensity (cps-count per seconds) distributions for the powder content.

SEM image of the powder shown in Figure 9a consisted of particles of complex geometry and various shapes, although it contained a mixture of large and small particles. The elemental composition of the powder, shown in Figure 9b, was determined by energy dispersive spectroscopy. Here, $\mathrm{Si}, \mathrm{Fe}, \mathrm{K}, \mathrm{P}, \mathrm{O}$ etc. element distributions are shown. Figure $9 \mathrm{c}$ shows that various compounds are present in the powder particles, including alkaline earth metal and alkaline compounds [32]. The powder content given in Figure $9 \mathrm{c}$ is $\mathrm{Fe}_{2} \mathrm{O}_{3}$, $\mathrm{K}_{3} \mathrm{FeO}_{2}, \mathrm{FeO}, \mathrm{Cr}_{2} \mathrm{O}_{3}, \mathrm{TiO}_{2}, \mathrm{NaO}_{2}, \mathrm{CaO}, \mathrm{MgO}, \mathrm{MnO}, \mathrm{SiO}_{2}, \mathrm{P}_{2} \mathrm{O}_{5}$, respectively. The density of the powder material is $2.51 \mathrm{~g} / \mathrm{cm}^{3}$. The powder contains properties similar to the lunar soil simulants (JSC-1A, FJS-1 and real lunar soil) [26] in terms of its oxide forms and density.

The dust was distributed evenly on the four PCB electrodes as depicted in Figure 2. A voltage of $11 \mathrm{kV}$ was then applied as a single channel at a frequency of $1 \mathrm{~Hz}$. The air breakdown voltage depends on the electrode opening, field shape, duration of the voltage, value of the electric field, and environmental factors such as temperature, pressure and humidity [46]. No arc or jump was observed in this study. Dust was found to be collected between the copper tracks within about $3 \mathrm{~min}$.

On the M1 and M2 plates (Figure 10), dust was concentrated in a straight line between the electrodes. However, on the M3 and M4 plates (Figure 11), dust accumulated as a line according to the shape of the electrodes. However, the shape of the electrode on the M3 and M4 plates did not improve the cleaning process and it was determined that the M1 and M2 plates would be more successful for the cleaning process.

The stationary wave produced by the single-phase excitation is not as efficient as multi-excitation for particle removal from the plate [8]. For this purpose, the M1 plate (Figure 12) and M2 plate (Figure 13) were reconfigured for multi-excitation. $0.56 \mathrm{~g}$ of $100-300 \mu \mathrm{m}$ dust was evenly distributed on the plates. The two plates were then subjected to 4-channel excitation for $3 \mathrm{~min}$, with $1 \mathrm{~Hz}$ frequency and $11 \mathrm{kV}$. 


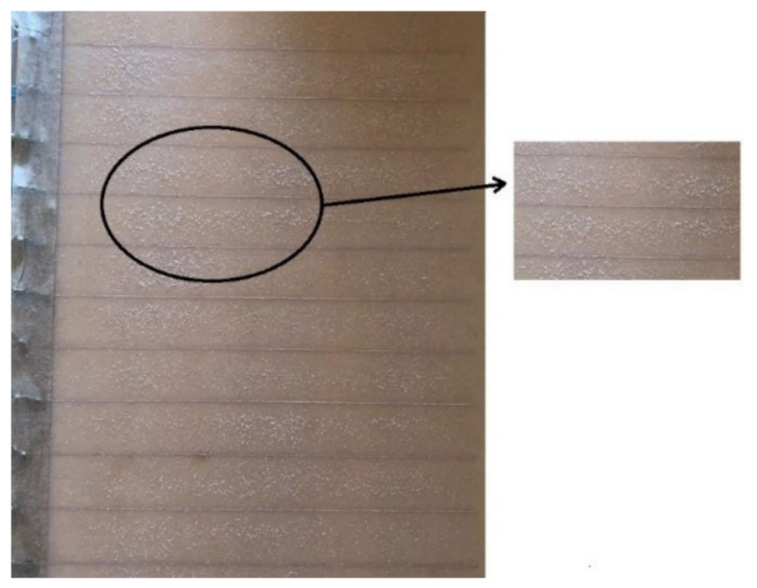

(a)

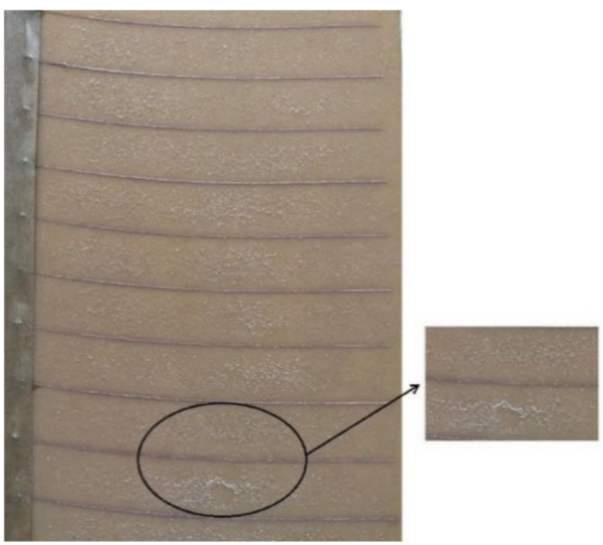

(b)

Figure 10. Dust distribution and accumulation as a result of single channel application to: (a) M1 model; (b) M2 model.

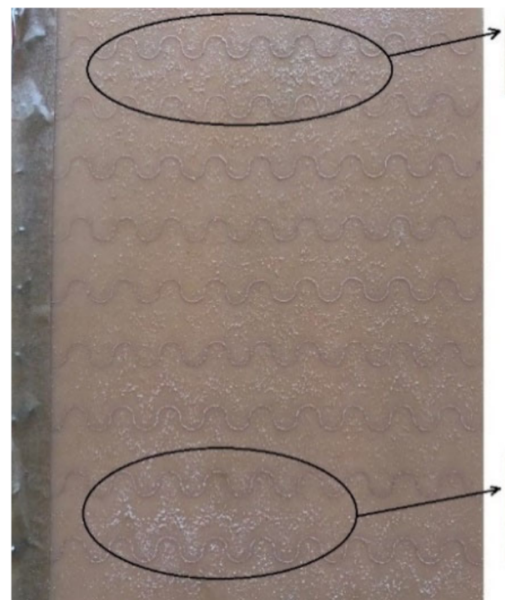

(a)

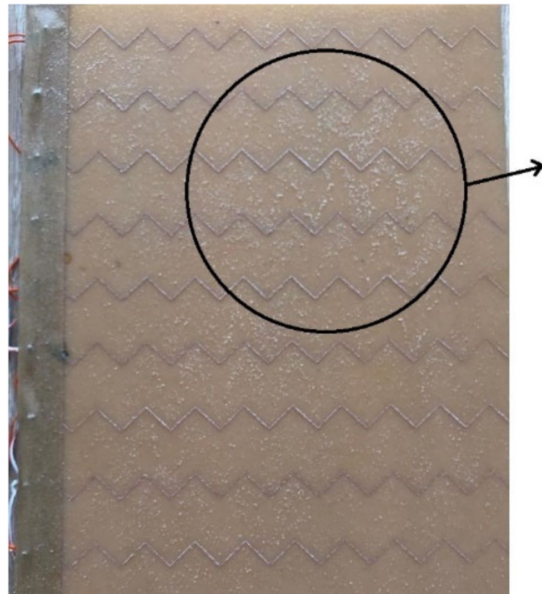

(b)

Figure 11. Dust distribution and accumulation as a result of single channel application to: (a) M3 model; (b) M4 model.

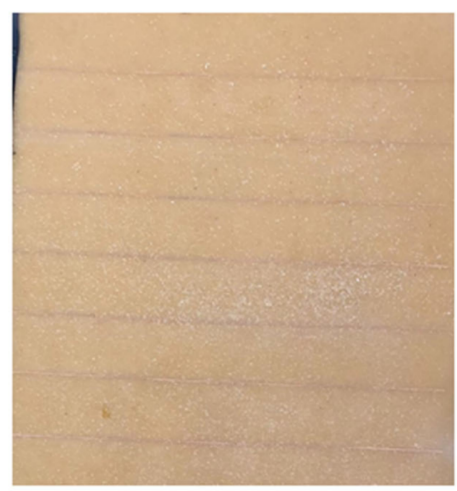

(a)

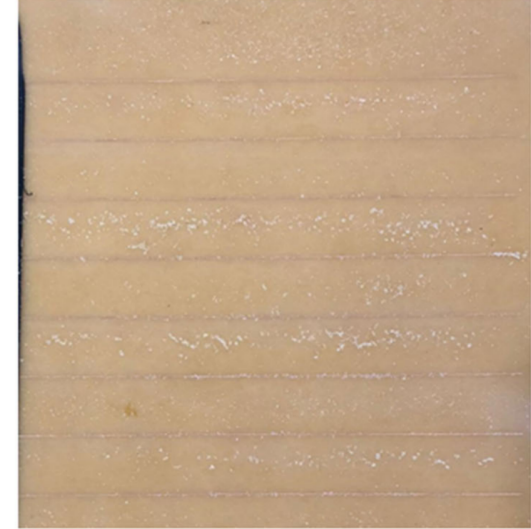

(b)

Figure 12. M1 model: (a) Before cleaning; (b) After cleaning. 


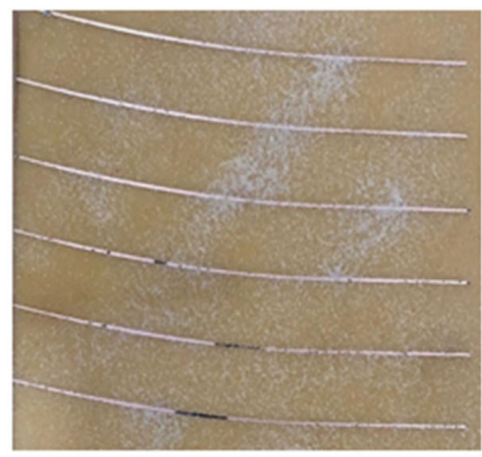

(a)

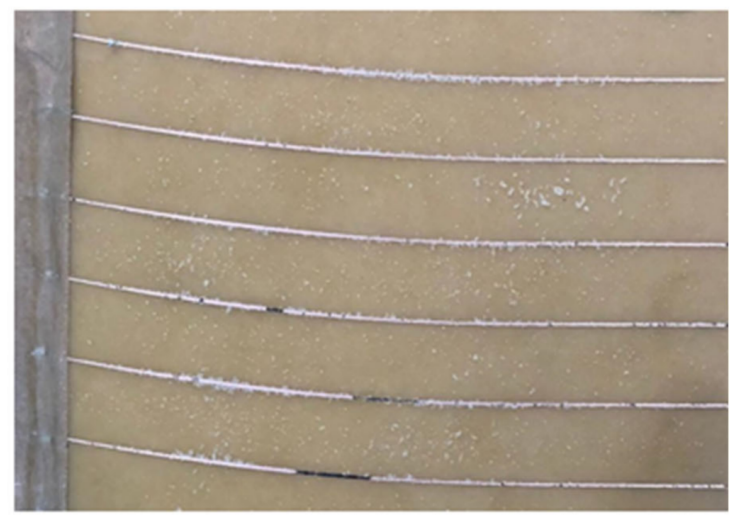

(b)

Figure 13. M2 model: (a) Before cleaning; (b) After cleaning.

The cleaning performance of the panels is generally expressed as the ratio between the weight of the dust before cleaning and the weight of the dust removed after cleaning $[14,23,43]$. The M1 plate (Figure 12) had $0.56 \mathrm{~g}$ of dust evenly spread over its surface. After cleaning, $0.10 \mathrm{~g}$ of dust remained, giving an efficiency of $82.14 \%$. The M1 plate drew 2.44 A during the cleaning process.

The M2 plate (Figure 13) had $0.56 \mathrm{~g}$ of dust evenly spread over its surface. After cleaning, $0.06 \mathrm{~g}$ of dust remained, giving an efficiency of $89.28 \%$. The M2 plate drew $1.33 \mathrm{~A}$ during the cleaning process at the same voltage and frequency. The M2 design is more efficient than the M1 design both in terms of cleaning and electrical power consumption.

\subsection{Cost Comparison}

The cost of cleaning PV panels with de-ionized pure water was determined for the 1 MW SPP field in the District of Bölücek of Sanliurfa province in Turkey.

The cleaning process has the requirement that the PV panels should be cleaned at least twice a year during the life-time of the plant to prevent the loss of panel efficiency going beyond the scope of insurance. The total cost of each clean, excluding the cost of the tractor, from Table 2 is $€ 7425.00$, giving an annual cost of $€ 14,850.00$ for cleaning the panels twice per year. The tractor costs are excluded as it is considered to be within the initial investment cost. This approach also results in a significant waste of water.

Table 2. Cleaning costs.

\begin{tabular}{ccccc}
\hline Product Used & Amount & Unit & Unit Price & Total Amount \\
\hline Cleaning Tractor & 1 & & $€ 20,000.00$ & $€ 20,000.00$ \\
\hline Tractor Diesel & 100 & L & $€ 0.80$ & $€ 800.00$ \\
\hline Cleaning Lady & 2 & & $€ 350.00$ & $€ 700.00$ \\
\hline Cleaning solution or pure water & 395 & L & $€ 15.00$ & $€ 5925.00$ \\
\hline
\end{tabular}

With electrostatic cleaning, the main running cost is the electrical energy consumed by the panels. Each M2 panel working with 4 channels will consume $1.33 \mathrm{~A}$ at a frequency of $1 \mathrm{~Hz}$ and a voltage of $11 \mathrm{kV}$, and $0.33 \mathrm{~A}$ for 1 channel. Working $8 \mathrm{~h}$ a day will consume $8 \times 24 \times 0.33=63.36 \mathrm{Wh}$ of energy at a voltage of $24 \mathrm{~V}$. This results in an energy consumption of $30 \times 63.36=1900$ Wh per month and 22,800 Wh annually. The power plant has 4800 panels, and a unit of electricity is priced at $0.07 € / \mathrm{kWh}$, according to the EMRA regulations. This results in a total approximate annual cost of $4800 \times 22,800 \mathrm{kWh} \times 0.07 € / \mathrm{kWh}=€ 7660$. The M2 design is $50 \%$ less expensive than tractor cleaning. Electrostatic cleaning is less expensive than cleaning with water and its derivatives, saves water and increases the output power of the PV panel. 
Turkey has 589 SPP, which includes 39 licensed and 550 unlicensed power plants, with further large power plants, such as the $1300 \mathrm{MW}$ solar power plant being built in Konya, being built. The cost of cleaning a $1 \mathrm{MW}$ solar power plant using traditional cleaning methods is $€ 14,850.00$ when performed twice a year, with a total of $395 \mathrm{~L}$ of solution and pure water being used. A $1300 \mathrm{MW}$ solar power plant will use approximately $1300 \times 395=513,500 \mathrm{~L}$. Moreover, these large power plants are often located in areas with water shortage; electrostatic cleaning is to be recommended in such places. Electrostatic cleaning is expected to become widespread in the future due to lower cleaning cost, timesaving, efficiency, water saving, and increased output from the PV panels. This is even more important after Turkey was placed in the group of countries experiencing water problems [47], and it becomes essential to implement water laws [47] and there is a need to introduce cleaning systems that do not require water.

\section{Conclusions}

This study presents a low-cost and efficient electrostatic cleaning system that reduces the effect of dust on the output power of PV panels. It can reduce the consumption of water in solar power plants, at a time when water is becoming scarce.

The study develops a novel system that provides a multi-channel output waveform to the electrode panel. The design of the electrode panel has no effect on the amount of radiation reaching the PV panel but is effective at removing dust. The geometry of the electrodes has been changed from simple straight lines to create a distribution in the electric field that increases the force exerted on the dust particles and thus efficiency.

Experiments conducted with a single channel demonstrated the M1 and M2 models provide greater accumulation of dust particles than the M3 and M4 models. However M3 and M4 models are presented as a new design that is effective at gathering particle samples, and may be useful for extraterrestrial applications.

Although the electric field of electrodes with simple geometry, such as M1 and M2, and thus uniform electric field can be estimated, it is difficult to determine the motion of the particles and cleaning performance, either analytically or numerically, due to the complexity of the equations $[30,38]$. However, in terms of cleaning performance, parallel and inclined electrodes showed high efficiency in dust cleaning in the four-channel operating condition.

Author Contributions: Conceptualization, S.A. and M.A.; methodology, S.A. and M.A.; software, S.A. validation, M.A., formal analysis, M.A.; investigation, M.A.; resources, S.A.; data curation, M.A.; writing—original draft preparation, S.A. and M.A.; writing—review and editing, S.A.; visualization, S.A.; supervision, S.A.; project administration, S.A.; funding acquisition, S.A. All authors have read and agreed to the published version of the manuscript.

Funding: This research received no external funding.

Institutional Review Board Statement: Not applicable.

Informed Consent Statement: Not applicable.

Data Availability Statement: Not applicable.

Acknowledgments: This study was produced from the master's thesis prepared by the first author under the supervision of the second author. The software was obtained from the Harran University under Research Project (project no: 18060).

Conflicts of Interest: No conflict of interest.

\section{References}

1. Kazem, A.A.; Chaichan, M.T.; Kazem, H.A. Dust effect on photovoltaic utilization in Iraq. Renew. Sustain. Energy Rev. 2017, 37, 734-749. [CrossRef]

2. Aly, S.P.; Gandhidasan, P.; Barth, N.; Ahzi, S. Novel dry cleaning machine for photovoltaic and solar panels. In Proceedings of the 3rd International Renewable and Sustainable Energy Conference (IRSEC), Marrakech, Morocco, 10-13 December 2015; pp. 1-6. [CrossRef]

3. Ghazi, S.; Sayigh, A.; Ip, K. Dust effect on flat surfaces-A review paper. Renew. Sustain. Energy Rev. 2014, 33, 742-751. [CrossRef] 
4. Abbas, K.K.; Al-Wattar, A.J.; Kasim, N.K. New technique for treatment of the dust accumulation from pv solar panels surface. Iraqi J. Phys. 2010, 8, 54-59.

5. Darwish, Z.A.; Kazem, H.A.; Sopain, K.; Alghoul, M.A.; Chaichan, M.T. Impact of some environmental variables with dust on solar photovoltaic(pv) performance: Review and research status. Int. J. Energy Environ. 2013, 7, 152-159.

6. Altıntaş, M.; Arslan, S. Analysis of Atmospheric Transported Particulate Matter and Investigation of Its Effects on Solar Panel. In Proceedings of the 9th European Conference on Renewable Energy Systems, Istanbul, Turkey, 21-23 April 2021; pp. 712-718.

7. Casanova, J.Z.; Piliougine, M.; Carretero, J.; Bernaola, P.; Carpena, P.; Mora-Lopez, L.; Sidrach-Cardona, M. Analysis of dust losses in photovoltaic modules. In Proceedings of the World Renewable Energy Congress, Malaga, Spain, 8-13 May 2011. [CrossRef]

8. Mazumder, M.K.; Sharma, R.; Biris, A.S.; Zhang, J.; Calle, C.; Zahn, M. Self-cleaning transparent dust shields for protecting solar panels and other devices. Part. Sci. Technol. 2007, 25, 5-20. [CrossRef]

9. Sulaiman, S.A.; Singh, A.K.; Mokhtar, M.M.M.; Bou-Rabee, M.A. Influence of Dirt Accumulation on Performance of PV Panels. Energy Procedia 2014, 50, 50-56. [CrossRef]

10. Al Shehri, A.; Parrott, B.; Carrasco, P.; Al Saiari, H.; Taie, I. Impact of dust deposition and brush-based dry cleaning on glass transmittance for pv modules applications. Sol. Energy 2016, 135, 317-324. [CrossRef]

11. Mazumder, M.; Horenstein, M.N.; Stark, J.W.; Girouard, P.; Sumner, R.; Henderson, B.; Sharma, R. Characterization of electrodynamic screen performance for dust removal from solar panels and solar hydrogen generators. IEEE Trans. Ind. Appl. 2013, 49, 1793-1800. [CrossRef]

12. Maghami, M.R.; Hizam, H.; Gomes, C.; Radzi, M.A.; Rezadad, M.I.; Hajighorbani, S. Power loss due to soiling on solar panel: A review. Renew. Sustain. Energy Rev. 2016, 59, 1307-1316. [CrossRef]

13. Chanchangi, Y.N.; Ghosh, A.; Sundaram, S.; Mallick, T.K. Dust and PV performance in Nigeria: A review. Renew. Sustain. Energy Rev. 2020, 21, 1-14. [CrossRef]

14. Chen, E.Y.T.; Ma, L.; Yue, Y.; Guo, B.; Liang, H. Measurement of dust sweeping force for cleaning solar panels. Sol. Energy Mater. Sol. Cells 2018, 179, 247-253. [CrossRef]

15. Zhao, W.; Lv, Y.; Wei, Z.; Yan, W.; Zhou, Q. Review on dust deposition and cleaning methods for solar PV modules. J. Renew. Sustain. Energy 2021, 13, 032701. [CrossRef]

16. Hudedmani, M.G.; Joshi, G.; Umayal, R.M.; Revankar, A. A comparative study of dust cleaning methods for the solar PV panels. Adv. J. Grad. Res. 2017, 1, 24-29. [CrossRef]

17. He, G.; Zhou, C.; Li, Z. Review of self-cleaning method for solar cell array. Procedia Eng. 2011, 16, 640-645. [CrossRef]

18. Lu, X.; Zhang, Q.; Hu, J. A linear piezoelectric actuator based solar panel cleaning system. Energy 2013, 60, 401-406. [CrossRef]

19. Vasiljev, P.; Borodinas, S.; Bareikis, R.; Struckas, A. Ultrasonic system for solar panel cleaning. Sens. Actuators A Phys. 2013, 200, 74-78. [CrossRef]

20. Masuda, S.; Washizu, M.; Iwadare, M. Separation of small particles suspended in liquid by nonuniform traveling field. IEEE Trans. Ind. Appl. 1987, 23, 474. [CrossRef]

21. Kawamoto, H.; Shibata, T. Electrostatic cleaning system for removal of sand from solar panels. J. Electrost. 2015, 73, 65-70. [CrossRef]

22. Biris, A.S.; Sanini, D.; Srirama, P.K.; Mazumder, P.K.; Sims, R.A.; Calle, C.I. Electrodynamic removal of contaminant particles and its applications. In Proceedings of the Conference Record 39th IEEE, IAS Annual Meeting, Seattle, WA, USA, 3-7 October 2004; pp. 1283-1286. [CrossRef]

23. Kawamoto, H.; Guo, B. Improvement of an electrostatic cleaning system for removal of dust from solar panels. J. Electrost. 2018, 91, 28-33. [CrossRef]

24. Alizadehyazdi, V.; Bonthron, M.; And Spenko, M. Optimizing electrostatic cleaning for dust removal on gecko-inspired adhesives. J. Electrost. 2020, 108, 103499. [CrossRef]

25. Mazumder, M.K. Self-Cleaning Solar Panels and Concentrators with Transparent Electrodynamic Screens. U.S. Patent No. 9,433,336, 6 September 2016.

26. Kawamoto, H.; Uchiyama, M.; Cooper, B.L.; McKay, D.S. Mitigation of lunar dust on solar panels and optical elements utilizing electrostatic traveling-wave. J. Electrost. 2011, 69, 370-379. [CrossRef]

27. Xu, L.; Shi, H.; Wang, L.; Xiao, W.; Li, Q.; Guo, J. The Efficiency Characteristic of Electrostatic Dust Precipitation Using Solar Energy. Therm. Sci. 2020, 24, 2857-2864. [CrossRef]

28. Chesnutt, J.K.; Ashkanani, H.; Guo, B.; Wu, C.Y. Simulation of microscale particle interactions for optimization of an electrodynamic dust shield to clean desert dust from solar panels. Sol. Energy 2017, 155, 1197-1207. [CrossRef]

29. Calle, C.I.; Buhler, C.R.; Mantovani, J.G.; Clements, S.; Chen, A.; Mazumder, M.K.; Nowicki, A.W. Electrodynamic shield to remove dust from solar panels on Mars. In Proceedings of the 41th Space Congress, Cape Canaveral, FL, USA, 27-30 April 2004; Volume I, pp. 202-206.

30. Calle, C.I.; Buhler, C.R.; Mcfall, J.L.; Snyder, S.J. Particle removal by electrostatic and dielectrophoretic forces for dust control during lunar exploration missions. J. Electrost. 2009, 67, 89-92. [CrossRef]

31. Guangming, W.; Dan, L.; Guangjian, X.; Tianlan, Y. The mechanism study of dust removal with transparent interdigitated electrodes. Integr. Ferroelectr. 2016, 171, 1-7. [CrossRef]

32. Yilbas, B.S.; Al-Qahtani, H.; Al-Sharafi, A.; Bahattab, S.; Hassan, G.; Al-Aqeeli, N.; Kassas, M. Environmental dust particles repelling from a hydrophobic surface under electrostatic influence. Sci. Rep. 2019, 9, 1-18. [CrossRef] 
33. Jiang, J.; Lu, Y.; Yan, X.; Wang, L. An optimization dust-removing electrode design method aiming at improving dust mitigation efficiency in lunar exploration. Acta Astronaut. 2020, 166, 59-68. [CrossRef]

34. Kawamoto, H. Improved detachable electrodynamic cleaning system for dust removal from soiled photovoltaic panels. J. Electrost. 2020, 107, 103481. [CrossRef]

35. Faes, A.; Petri, D.; Champliaud, J.; Jonas Geissbühler, J.; Badel, N.; Levrat, J.; Roustom, B.; Hessler-Wyser, A.; Wyrsch, N.; Ballif, C.; et al. Field test and electrode optimization of electrodynamic cleaning systems for solar panels. Wiley Prog. Photovolt. Prog. Photovolt. Res. Appl. 2019, 27, 1020-1033. [CrossRef]

36. Kawamoto, H. Sampling of small regolith particles from asteroids utilizing an alternative electrostatic field and electrostatic traveling wave. J. Aerosp. Eng. 2014, 27, 631-635. [CrossRef]

37. Sharma, R.; Wyatt, C.A.; Zhang, J.; Calle, C.I.; Mardesich, N.; Mazumder, M.K. Experimental evaluation and analysis of electrodynamic screen as dust mitigation technology for future mars missions. IEEE Trans. Ind. Appl. 2009, 45, 591-596. [CrossRef]

38. Calle, C.I.; Mcfall, J.L.; Buhler, C.R.; Snyder, S.J.; Arens, E.E.; Chen, A.; Trigwell, S. Dust particle removal by electrostatic and dielectrophoretic forces with applications to NASA exploration missions. In Proceedings of the ESA Annual Meeting on Electrostatics, ESA Minneapolis, MN, USA, 17-19 June 2008.

39. Manyapu, K.K.; De Leon, P.; Peltz, L.; Gaier, J.R.; Waters, D. Proof of concept demonstration of novel technologies for lunar spacesuit dust mitigation. Acta Astronaut. 2017, 137, 472-481. [CrossRef]

40. Mazumder, M.K.; Horenstein, M.N.; Joglekar, N.R.; Sayyah, A.; Stark, J.W.; Bernard, A.A.; Griffin, A.C. Mitigation of dust impact on solar collectors by water-free cleaning with transparent electrodynamic films: Progress and challenges. IEEE J. Photovolt. 2017, 7, 1342-1353. [CrossRef]

41. Syafiq, A.; Pandey, A.K.; Adzman, N.N.; Abd Rahim, N. Advances in approaches and methods for self-cleaning of solar photovoltaic panels. Sol. Energy 2018, 162, 597-619. [CrossRef]

42. Altintaş, M.; Arslan, S. Pvsyst ile Güneş Paneli Kirlik Etkilerinin İncelenmesi: Şanlıurfa Güneş Enerjisi Santrali Örneği, 2nd ed.; Eda Altunel; Gece Kitaplığ1: Ankara, Turkey, 2020; pp. 65-84. Available online: https://www.gecekitapligi.com/Webkontrol/ uploads/Fck/cilt1_7.pdf (accessed on 28 May 2021).

43. Altıntaş, M.; Arslan, S. The Study of Dust Removal Using Electrostatic Cleaning System for Solar Panels. Sustainability 2021, 13, 9454. [CrossRef]

44. Sayyah, A.; Horenstein, M.N.; Mazumder, M.K.; Ahmadi, G. Electrostatic force distribution on an electrodynamic screen. J. Electrost. 2016, 81, 24-36. [CrossRef]

45. Jiang, J.; Lu, Y.; Zhao, H.; Wang, L. Experiments on dust removal performance of a novel PLZT driven lunar dust mitigation technique. Acta Astronaut. 2019, 165, 17-24. [CrossRef]

46. Özkaya, M. Yüksek Gerilim Tekniği, Cilt 1, Cilt 2; Birsen Yayınevi: Istanbul, Turkey, 1996.

47. Aküzüm, T.; Çakmak, B.; Gökalp, Z. Türkiye'de su kaynakları yönetiminin değerlendirilmesi. Int. J. Agric. Nat. Sci. 2010, 3, 67-74. 